\title{
HISTÓRIA DA MATEMÁTICA EM UM CURSO DE FORMAÇÃO DE PROFESSORES: ALGUNS APONTAMENTOS
}

\section{HISTORY OF MATHEMATICS IN A TEACHER TRAINING \\ COURSE : SOME NOTES}

\author{
Ana Chiummo ${ }^{1}$ \\ Universidade Paulista \\ Emilio Celso de Oliveira ${ }^{2}$ \\ Prefeitura de São Paulo/Universidade Paulista
}

\begin{abstract}
Resumo
Este artigo apresenta a História da Matemática como disciplina essencial na formação de professores. O objetivo é discutir como esta disciplina pode concorrer para essa formação, as contribuições que ela pode dar na construção e significação dos conhecimentos matemáticos e sua possível influência na prática pedagógica desses professores. As seguintes questões motivaram esse estudo sobre o curso de graduação: Por que estudar História da Matemática? Qual a percepção dos alunos acerca da importância de se estudar a História da Matemática? A metodologia de pesquisa empregada é uma pesquisa qualitativa, com amostra de respostas de alunos do $6^{\circ}$ semestre da Universidade Paulista, que expressaram suas percepções sobre a vivência do estudo da disciplina no $1^{\circ}$ semestre de 2015. A literatura relacionada e as recomendações curriculares dos Parâmetros Curriculares Nacionais destacam a relevância do valor didático da História da Matemática. A análise de conteúdo das respostas dos participantes indica que o estudo da História da Matemática pode contribuir para que o futuro professor dê significado aos currículos escolares do Ensino Básico e, ao agregar conhecimentos sobre as teorias matemáticas e os grandes matemáticos, utilize a História também como um recurso didático. Indicam ainda que é fundamental ao futuro professor compreender a origem e a motivação para 0 desenvolvimento dos diversos conceitos matemáticos, para melhor atuação no processo de ensino e aprendizagem. Sendo assim, o conhecimento que o professor tem do que vai ensinar influencia suas escolhas e suas formas de ensinar, em particular, incorporando o recurso didático da História da Matemática.
\end{abstract}

Palavras-chave: Educação Matemática; História da Matemática; Formação de Professores.

\section{Abstract}

This article presents the History of Mathematics as an essential discipline in the teachers' education. The aim is to discuss how this course can apply for this education,

\footnotetext{
1 anachiummo@uol.com.br.

2 emilio.celso@gmail.com.
} 
the contributions it can make in the construction and significance of mathematical knowledge and its possible influence on the teaching practice of these teachers. The following questions have motivated this study about the undergraduated degree: Why study History of Mathematics? What is the perception of the students about the importance of studying the history of mathematics? The research methodology is a qualitative research, with sample from students of the 6th semester at the Paulista University, who expressed their perceptions about the experience of the study of the subject in the 1 st half of 2015. The related literature and curriculum recommendations of the Parâmetros Curriculares Nacional highlight the relevance of the educational value of the history of mathematics. The content analysis of the responses from participants indicates that the study of History of Mathematics can contribute to the future teacher giving meaning to the curricula of basic education, and to add knowledge of mathematical theories and the great mathematicians, use history as well as an educational resource. It also indicates that it is essential to future teachers understand the origin and motivation for the development of several mathematical concepts to better performance in the process of teaching and learning. Thus, the knowledge that the teacher has to teach that will influence their choices and their ways of teaching, in particular, incorporating the teaching tool of the History of Mathematics.

Keywords: Mathematical Education; History of Mathematics; Teachers' Education.

\section{Introdução}

A temática desta comunicação insere-se nos estudos da temática História da Matemática e a Formação do Professor de Matemática.

O texto apresenta alguns apontamentos sobre a essencialidade da História da Matemática como disciplina na formação inicial de professores de Matemática.

Uma discussão inicial procura situar a seguinte questão: Por que estudar História da Matemática em um curso de graduação? Posto isso, buscamos conhecer qual a percepção dos alunos acerca da importância de se estudar a História da Matemática na Licenciatura, segundo o ponto de vista de alunos concluintes de graduação?

Essas questões mobilizaram as reflexões que serão apresentadas sobre o estudo de História da Matemática na graduação.

Temos como objetivos:

a) discutir como esta disciplina pode concorrer para essa formação dos alunos;

b) analisar como o estudo de História da Matemática pode contribuir na construção e significação dos conhecimentos matemáticos;

c) compreender a possível influência na prática pedagógica dos futuros professores. 
Em nosso entendimento, é fundamental ao futuro professor construir uma perspectiva sobre a História da Matemática que ajude na compreensão sobre a importância da origem e a motivação histórica para o desenvolvimento dos diversos conceitos matemáticos. Acreditamos que essa perspectiva histórica possa se constituir em um fator que tem implicações sobre a atuação no processo de ensino e aprendizagem.

\section{Aspectos metodológicos}

A metodologia do estudo realizado, de caráter exploratório, consistiu de dois momentos: uma pesquisa bibliográfica e uma pesquisa qualitativa.

No primeiro momento, fizemos uma pesquisa bibliográfica. Apresentamos a ementa do curso de Licenciatura em Matemática da Universidade Paulista, procurando apresentar a concepção da disciplina.

Em seguida, fizemos um recorte da literatura relacionada ao nosso tópico para introdução de nosso estudo (CRESWELL, 2010, p. 52).

A consulta à literatura relacionada teve intuito a busca de compreensão da importância da disciplina História da Matemática em um curso de graduação e de como a disciplina pode concorrer para formação dos professores. Em especial, trazemos as recomendações acerca do emprego didático da História da Matemática nos Parâmetros Curriculares Nacionais (Brasil, 1998).

Um segundo momento consistiu em uma pesquisa qualitativa, da qual destacamos três características:

\footnotetext{
- ambiente natural - Os pesquisadores qualitativos tendem a coletar dados no campo e no local em que os participantes vivenciam a questão ou problema que está sendo estudado.

(...)

- significado dos participantes - Em todo processo de pesquisa qualitativa, o pesquisador mantém um foco na aprendizagem do significado que os participantes dão ao problema ou questão, e não ao significado que os pesquisadores trazem para a pesquisa ou que os autores expressam na literatura.

(...)

- Interpretativo - A pesquisa qualitativa é uma forma de investigação interpretativa em que os pesquisadores fazem uma interpretação do que enxergam, ouvem e entendem. Suas interpretações não podem ser separadas de suas origens, história, contextos e entendimentos anteriores. (CRESWELL, 2010, p. 208-209)
}

Essas características são relevantes para o estudo que empreendemos. Assim, realizamos a aplicação de um instrumento de coleta de dados com questões abertas aos 
alunos do $6^{\circ}$ semestre de graduação da Universidade Paulista. Nosso intuito foi captar a percepção dos alunos sobre a vivência do estudo da disciplina História da Matemática.

Para compreensão das respostas dos alunos às questões abertas do instrumento de coleta de dados, empregamos o procedimento metodológico de análise dos conteúdos.

\title{
História da Matemática na Educação Matemática: um recorte
}

A literatura relacionada à História da Matemática é bastante ampla, no que se refere à defesa do uso desse recurso didático nas aulas de Matemática. Em vista disso, optamos por um recorte de autores e documentos, no caso os exemplares do PCN, que julgamos significativos algumas reflexões realizadas.

Uma primeira questão formulada por nós foi a seguinte: Por que estudar História da Matemática em um curso de graduação? Essa questão é bastante ampla, contudo queremos circunscrevê-la ao âmbito do processo de ensino e aprendizagem da Educação Matemática.

Miorim e Miguel (2011) enfatizam diversos aspectos sobre a justificativa de se estudar História da Matemática, dentro os quais destacamos:

\begin{abstract}
A matemática como uma criação humana; As razões pelas quais as pessoas fazem matemática; As necessidades práticas, econômicas e físicas que servem de estímulo ao desenvolvimento das ideias matemáticas; (...); A curiosidade estritamente intelectual que pode levar a generalização e extensão de ideias e teorias. (MIORIM e MIGUEL, 2011, p. 53)
\end{abstract}

D'Ambrosio (2000) discute o caráter prático da História da Matemática, entendendo que seu estudo na escola

\begin{abstract}
serve não somente para alunos e professores, mas também para os pais e para o público em geral, porque a matemática, de uma forma ou outra, é praticada, desde os tempos pré-históricos, por todos os seres humanos, muitas vezes, sem ser reconhecida. Não é reconhecido pois geralmente não é formalizada, como no atual modelo acadêmico. (D'AMBROSIO, p. 243-244)
\end{abstract}

D'Ambrósio (2010) defende que o estudo de História da Matemática ao longo da escolaridade, não apenas em nível superior, deve ter como objetivos:

1. situar a Matemática como uma manifestação cultural de todos os povos, em todos os tempos, como a linguagem, os costumes, os valores, as crenças e os hábitos e, como tal, é diversificada nas suas origens e na sua evolução; 2. mostrar que a Matemática que se estuda nas escolas é uma das muitas formas de Matemática desenvolvidas pela humanidade; 3. destacar que essa Matemática, isto é, a Matemática Escolar, teve sua origem nas culturas da Antiguidade Mediterrânea e se desenvolveu ao longo da Idade Média em 
toda a Europa e somente a partir do século XVII se organizou como um corpo de conhecimentos, comum estilo próprio; 4. saber que desde então essa Matemática, isto é, a Matemática Escolar, tornou-se indispensável como base para a ciência, a tecnologia e a economia. (D'AMBROSIO, 2000, p. 246)

A presença da História da Matemática nos currículos prescritos relaciona-se com orientações e resultados de pesquisas da área de Educação.

Brolezzi (1991, p. 62), em sua pesquisa acerca do valor didático dessa área do conhecimento, ponderou que alguns componentes justificam sua inserção no currículo de Matemática. Um primeiro componente diz respeito ao fato de se tornar evidencia que a forma com que os conceitos foram se estruturando é distinta da lógica da sistematização do conhecimento matemático.

Um segundo componente consiste na construção histórica da simbologia matemática, o que pode ser uma possibilidade de acesso a seus símbolos (BROLEZZI, 1991, p. 62).

Um terceiro componente é que o conhecimento histórico pode propiciar uma visão de conexão entre os conceitos matemáticos (BROLEZZI, 1991, p. 62).

Um último componente diz respeito à possibilidade de o conhecimento histórico ser um recurso para a contextualização do conhecimento matemático, mostrando ora como os conceitos foram surgindo em resposta a aplicação prática, ora por especulação intelectual dos matemáticos (BROLEZZI, 1991, p. 62-63).

Para o professor em formação, essas componentes relativas ao conhecimento histórico, embora fundamentais, tornam a inserção da História da Matemática um desafio, pela dificuldade de tratamento dado a essas componentes ao se pensar o currículo e, consequentemente, ao que se pode alcançar pelo trabalho de sala de aula, o que tem sido objeto de críticas.

Radford (1997, p. 26), pesquisador estadunidense, considera que o uso educacional da História da Matemática com propósitos didáticos ficava em um nível superficial, aquém das possibilidades para que esse recurso pudesse contribuir para o trabalho do professor. Sua crítica está centrada na observação de que a presença da História da Matemática no trabalho do professor ora se resumia a relato de anedotas históricas dos alunos, ora se restringia a um repertório de problemas organizados cronologicamente a serem "importados" para sala de aula, que os alunos têm de resolver. 
Para superar essa visão ingênua das possibilidades do recurso didático da História da Matemática, como destaca Brolezzi (1991), Radford (1997, p. 26) sugere a exploração do desenvolvimento do conhecimento matemático, estabelecendo uma conexão entre o significado do conceito do ponto de vista do matemático do passado e o do presente. Para isso, é importante que o matemático do presente, e por extensão o professor de Matemática, não incorra em um olhar enviesado culturalmente, por dispor de outros recursos para compreensão dos conceitos matemáticos.

Atentos a essas críticas, o documento Parâmetros Curriculares Nacionais para o Ensino Fundamental (PCN) (Brasil: 1998) recomenda a utilização da História da Matemática, procurando superar as críticas referentes tanto aos cuidados para não empobrecimento desse recurso didático pelo professor, quanto ao entendimento de seu valor cultural no aprendizado de Matemática.

Assim, os elaboradores do PCN sugerem que o professor compreenda que o conhecimento matemático estruturou-se de maneira particular a cada cultura:

\begin{abstract}
A Matemática desenvolveu-se seguindo caminhos diferentes nas diversas culturas. $\mathrm{O}$ modelo de Matemática hoje aceito, originou-se com a civilização grega, no período que vai aproximadamente de 700 a.C. a 300 d.C., abrigando sistemas formais, logicamente estruturados a partir de um conjunto de premissas e empregando regras de raciocínio preestabelecidas. A maturidade desses sistemas formais foi atingida no século XIX, com o surgimento da Teoria dos Conjuntos e o desenvolvimento da Lógica Matemática. (BRASIL, 1998, p. 25)
\end{abstract}

Neste artigo, procuramos questionar os futuros professores sobre o emprego da História da Matemática como recurso didático para o desenvolvimento de atividades em sala de aula, para uma perspectiva complementar à literatura referente a esse tema.

\title{
Análise dos dados
}

Os instrumentos de coletas de dados preenchidos pelos participantes de nosso estudo, alunos do $6^{\circ}$ semestre matriculados na disciplina História da Matemática no 1 $\underline{\mathrm{o}}$ semestre de 2015 foram digitados e depois lidos para análise de conteúdos.

Trivinos (1987, apud SILVA et al., 2005, p. 75-76) conceitua assim as etapas da análise dos conteúdos: pré-análise, quando o pesquisador se faz a organização do material; a descrição analítica, etapa em que o material reunido constitui o corpus da pesquisa; a interpretação referencial, a fase de análise propriamente dita; e o recorte 
de conteúdos, a análise dos conteúdos coletados e organizados buscando alcançar o sentido profundo do conteúdo ou passar ao largo das ideias essenciais.

Para avaliar a percepção dos alunos acerca do valor didático da História da Matemática, a codificação dos instrumentos de coleta de dados empregada teve como categorias de análise as componentes sugeridas por Brolezzi (1991, p. 62-63), a saber:

- origem e sistematização do conhecimento matemático;

- significado da linguagem matemática;

- visão curricular;

- contextualização de conteúdos matemáticos.

Neste artigo, as percepções dos alunos sobre a importância da História da Matemática e o interesse de utilizar esse recurso em sala de aula foram selecionadas segundo essas componentes.

\section{Interpretação dos dados}

Nesta seção apresentamos a percepção dos alunos acerca do valor didático da História da Matemática, segundo as componentes escolhidas em nosso estudo.

No que diz respeito à origem e sistematização do conhecimento matemático, procuramos no texto palavras relativas à origem ou surgimento do conhecimento matemático.

Em relação a essa componente, destacamos algumas percepções dos alunos. O estudo da História da Matemática propicia localizar na história o momento e a motivação do surgimento do conceito surge:

Pontuar dentro de nossa história surgimento dos conceitos matemáticos e com o homem absorveu este conhecimento. (Participante 1)

Como surgiu cada tese e quando e porquê surgiu é muito interessante. (Participante 2)

Mostrar o porquê do desenvolvimento matemático, conforme a época em que se vivia. (Participante 5)

Outra percepção é que o conhecimento de História da Matemática pode evidenciar os processos históricos de compreensão dos conceitos, por diferentes culturas:

Quanto aos aspectos positivos podemos citar o conhecimento da matemática em diferentes culturas, a possibilidade de comparar diversos processos matemáticos do passado com os atuais ou de diversas épocas, a possibilidade de conhecer obras de grandes matemáticos ao longo de vários séculos. (Participante 3) 
Nesse trecho estão envolvidas ideias de relativas ao surgimento e ao desenvolvimento, no sentido de se conhecer as motivações, o que dá relevância ao estudo de História da Matemática.

As pistas procuradas nas respostas dos participantes sobre a componente significado da linguagem matemática foi encontrada por meio do substantivo demonstração. Assim, um participante apontou a demonstração como um aspecto que o estudo histórico pode destacar:

Como futuro professor a história da matemática é muito relevante, pois em sala de aula poderemos explicar aos nossos alunos o porquê. Desse modo, a demonstração por meio da história e um recurso, para os professores demonstrarem os avanços e as mudanças durante o tempo nos conteúdos. (Participante 7)

A componente visão curricular foi manifestada pelo substantivo conteúdo. Um participante se referiu a essa componente:

Saber explicar e definir os conteúdos matemáticos desenvolvidos em sala de aula. (Participante 1)

Por fim, a contextualização dos conteúdos matemáticos compareceu na fala de participantes do nosso estudo

\begin{abstract}
A história da matemática aplicada em sala de aula é fundamental para instigar os alunos sobre como surgiram alguns conceitos matemáticos e sua importância par atender as necessidades da época. Nos dias atuais, é preciso contextualizar alguns assuntos para trazer à realidade do aluno a aplicabilidade, ou não, do tema abordado. (Participante 8)]

Na História da Matemática, podemos buscar diversas informações para complementar um estudo no qual estamos trabalhando ou seja, encontramos nela elementos para agregar qualquer estudo matemático. Mas por ser realizada e escrita por homens em determinados momentos de sua realidade e necessidade, nem sempre estará completa. (Participante 9)
\end{abstract}

Isso é reflexo da discussão atual sobre a contextualização do conhecimento matemático. Em especial, nos textos dos participantes compareceram ideias associadas à contextualização, ora se referindo às aplicações práticas, ao papel no entendimento de fenômenos ou à compreensão de situações sociais:

Nesse ponto gostaríamos de fazer um aparte sobre a noção de contextualização. Maioli (2012, p. 7-8), ao examinar o conceito, considera que a contextualização está relacionada aos estudos de Pires (2002) acerca da rede de significações; à aprendizagem significativa proposta por Ausubel; ao papel de instrumentos e signos na mediação entre relações sociais e funções mentais superiores de Vygotsky; às concepções da linguagem da Linguística. E, sobretudo, aponta que 


\begin{abstract}
Apresentar atividades com aplicações de conteúdos matemáticos em outras áreas, pensando em aproximação do conteúdo escolar com o real, pode ser uma estratégia para a contextualização, mas não deve ser confundida com a contextualização em si. Tais atividades não garantem, por si só, um conhecimento contextualizado, ou seja, não garantem atribuição de significados aos conteúdos matemáticos. Elas têm sua importância, mas (...) precisam estar associadas a outras condições que permitam o estabelecimento de relações entre o sujeito e o objeto de estudo. (MAIOLI, 2012, p. 200)
\end{abstract}

A contextualização se trata de um conceito bastante abrangente, sendo que trazer ao aluno o conhecimento histórico dos conceitos matemáticos é aspecto que agrega significados ao conteúdo que se estuda.

\title{
Considerações finais
}

O estudo realizado, de caráter exploratório, evidencia algumas pistas acerca de apresentar a História da Matemática aos alunos de graduação.

A análise de conteúdo das respostas dos participantes indica que o estudo da História da Matemática pode contribuir para que o futuro professor dê significado aos currículos escolares do Ensino Básico e, ao agregar conhecimentos sobre as teorias matemáticas e os grandes matemáticos, utilize a História também como um recurso didático.

Indicam ainda que é fundamental ao futuro professor compreender a origem e a motivação para o desenvolvimento dos diversos conceitos matemáticos, para melhor orientação didática do processo de ensino e aprendizagem.

Sendo assim, o conhecimento que o professor precisa ter dos conteúdos que vai ensinar influencia suas escolhas e suas formas de ensinar. Em particular, esse conhecimento interfere em como pode ser incorporado o recurso didático da História da Matemática.

\section{Referências}

BOYER, C. B. \& MERZBACH, U. C. (2011) Uma História da Matemática. 3a ed. Hoboken, John Wiley \& Sons,.

BRASIL. (1997). MINISTÉRIO DA EDUCAÇÃO. Secretaria do Ensino Fundamental. Parâmetros Curriculares Nacionais. $1^{\circ}$ e $2^{\circ}$ Ciclos do Ensino Fundamental. Matemática. Brasília : MEC/SEF, 142 p. 
BRASIL. (1998). MINISTÉRIO DA EDUCAÇÃO. Secretaria do Ensino Fundamental. Parâmetros Curriculares Nacionais. $3^{\circ}$ e $4^{\circ}$ Ciclos do Ensino Fundamental. Matemática. MEC/SEF, 148 p.

BROLEZZI, A. C. (1991). A Arte de Contar: uma Introdução ao Estudo do Valor Didático da História da Matemática. (Mestrado em Educação) São Paulo: FEUSP.

CRESWELL, J. W. Projeto de pesquisa: métodos qualitativo, quantitativo e misto. $2^{\mathrm{a}}$ ed. Porto Alegre: Artmed, 2010.

D'AMBROSIO, U. (2000). A interface entre história e matemática: Uma visão histórico-pedagógica. In John A. Fossa (Org.). Facetas do Diamante. Rio Claro, SP: Editora da SBHMat, pp. 241-271.

MAIOLI, M. (2011). Os significados da contextualização na Matemática do Ensino Médio. Tese (Doutorado em Educação Matemática). São Paulo, PUC-SP.

MIGUEL, A; MIORIM, M. A. História na Educação Matemática: propostas e desafios. 2. ed. Belo Horizonte: autentica editora,2011. 208 p.

RADFORD, L. (1997). On Psychology, Historical Epistemology and the Teaching of Mathematics: Towards a Socio-Cultural History of Mathematics. In: Forthe Learning of Mathematics, 17 (1), 26-33. 